\title{
Investigation of regularities of brittle fracture formation around mine workings in overstressed rocks at the mines of Kirovsk branch of JSC «Apatit»
}

\author{
Pavel Korchak ${ }^{1 *}$ \\ ${ }^{1}$ Kirovsk branch of JSC «Apatit», Kirovsk, Russia
}

\begin{abstract}
The article is devoted to the investigation of brittle fracture formation in underground mines of Kirovsk branch of JSC "Apatit" by applying numerical simulation and subsequent comparison with the results of field data. It includes the results of studies of rock failure forms with different directions, values and stress ratio, as well as the measures to reduce stress by drilling relief holes. Brittle fracturing and dependencies of its formation based on many factors, including mining, geological and geomechanical factors were researched. The results serve as the basis for the next research aimed at searching and grounding the effective ways to stabilize mine tunnels in case of brittle fracturing.
\end{abstract}

\section{Introduction}

At the Khibiny apatite mines, all forms of dynamic rock pressure are noted: from external signs of rock-bump hazard (rock bulking, dynamic seismic induced rockfall, strainburst) to the actual rockbursts of both local and regional origin. All these events are to some extent related to the features of stress-strain rock condition, characterized by increased horizontal (almost horizontal) stresses, much higher than the vertical ones.

The main, envisaged by the regulations, way to reduce stress on the outline (turn into unhazardous condition) is drilling the relief holes and boreholes [1]. This method is based on the application of rock pressure energy for interhole pillar rashing. In this case, in the outline adjacent to the line of relief holes, due to the stretching force, sloughing zone is formed, which provokes cutter break forming, resembling in configuration the dynamic rockfall, which also effects further stability, and, therefore, should be taken into account when choosing a method of stabilization.

Currently, one of the main priorities to improve the stabilization in underground mines of Kirovsk branch of JSC "Apatit" is to explore the methods to support and to maintain the excavation in the overstressed rock mass. This search activity is based on the studies presented in this article.

In this regard, the objectives of the study were as follows:

\footnotetext{
*Corresponding author: Pkorchak@phosagro.ru
} 
1. Study of regularities of brittle fracture formation, including the increased stresses, different directions of their activity, as well as instantaneous and fatigue rock strength;

2. Study of regularities of brittle fracture formation including relief holes' availability.

\section{Theory and research procedure}

Rock failure next to the mine working at the mines of Kirovsk branch of JSC "Apatit", as well as at the other enterprises, depends on stress condition, rock strength and structural rock faulting. If rock stress is low $\sigma_{-} 1 / \sigma_{-}(c, i)<0.15$, the rockfall into the developed space is mainly determined by the level of fracturing, that is, the number and the orientation of fractures relative to the mine tunnel position. However, as stress level increases, the rockfall into the developed space is associated with new fracture formation oriented parallel to the outline. At medium depths, the fractures are localized in the peripheral outline area, but as the stress increases, the area of brittle fracture also expands. The rock volume in the brittle fracture zone determines the support load and must be defined to improve the reliability of temporary or permanent support parameters [2].

Brittle rock failure close to the excavations is defined as rock bulking or rock spalling, as a result a V-shaped zone is formed, and the rockfall can occur both as monotonous almost quasistatic failure, or as dynamic failure, local rockburst. The size of these zones varies from a few centimeters to a meter, sometimes even more. In general, regularities of brittle fracture formation at the mines of Kirovsk branch of JSC "Apatit" coincide with widely recognized, stated in various sources, for example, in [3].

At the first stage of the study, it was necessary to calculate stress-strain rock condition close to the excavations and to assess the brittle break zone for the mines of Kirovsk branch of JSC "Apatit".

The studies were carried out on the grounds of numerical simulation including the nonlinear Hoek-Brown failure criterion [4].

On the grounds of plane deformation, brittle fracture formation near the excavations without relief slot along the length of the mine working or incomplete response of relief holes were studied. The calculations were made for the inclination angles of principal stress areas in the global coordinate system, 0,15 and $30^{\circ}$, that corresponds to the mining terms at the mines of Kirovsk branch of JSC "Apatit" [5, 6].

Boundary conditions of the models - standard for geomechanical issues. Shifts in the direction perpendicular to the model boundaries are prohibited. The initial field of stress condition was set as a tensor of principal stress. When rotating basic areas relative to the global coordinate system, stress tensor was recalculated as follows

$$
\sigma^{r}=\operatorname{ToT}^{\mathbf{T}}
$$

where $\sigma$ - stress tensor in the global coordinate system; $\sigma^{\prime}$ - stress tensor in the global coordinate system after rotation of basic areas by corresponding angle; $T$ - stress transformation matrix $[7,8]$.

Stress-strain state calculation is performed for the conditions when the ratio of maximum stress on the outline to the strength of undisturbed rock sample corresponds to $0.5,0.7$, and 1.0. Taking the rock strength equal to $150 \mathrm{MPa}$, and given the magnitude of vertical stresses equal to $15 \mathrm{MPa}$, we obtain the following initial rock stress (table 1). The ratio between stresses is chosen using actual (full-scale) measurements of their values at the mines of Kirovsk branch of JSC "Apatit”. 
Table 1. Initial field of stress condition

\begin{tabular}{|c|c|c|c|}
\hline$\frac{\sigma_{\text {emax }}}{\sigma_{\mathrm{ci} i}}$ & $\sigma_{1}, \mathrm{MPa}$ & $\sigma_{2}, \mathrm{MPa}$ & $\sigma_{3}, \mathrm{MPa}$ \\
\hline 0.5 & 30 & 15 & 15 \\
\hline 0.7 & 40 & 20 & 15 \\
\hline 1.0 & 55 & 27.5 & 15 \\
\hline
\end{tabular}

When performing the calculations it is accepted that the value of long-term rock strength relative to its initial value, that is, the index of long-term strength, is 0.9 on average.

\section{Research data}

Research data showed that brittle fracture zone at $\frac{\sigma_{\max }}{\sigma_{\mathrm{gi}}}=\mathbf{0 . 5}$ is mainly formed in the peripheral outline area, and its size varies from 0.15 to $0.25 \mathrm{~m}$. Depending on the orientation of principal stresses relative to the global coordinate system, the position of brittle fracture zone shifts from the dome to the wall by approximately the same angle. When increasing the initial stress to $\frac{\sigma_{9 \max }}{\sigma_{\mathrm{ei}}}=\mathbf{0 . 7}$, the area of brittle fracture expands to $0.8-0.9 \mathrm{~m}$, and it adopts a $\mathrm{V}$-shape. Subsequent stress increasing $\left(\sigma_{-}(\theta \cdot \max ) / \sigma_{-}(\mathrm{c}, \boldsymbol{i})=1.0\right)$ leads to the sharp growth of brittle fracture zone. Over time, strength range also leads to the growth of brittle fracture zone by $1.3-1.8$ times. The higher the value is, the smaller the value was at the time of mine development. Absolute sizes of brittle fracture zone obtained for all calculated cases are represented in table (table 2). The drawings predicting brittle fracturing are shown in figures 1 and 2.

During the second stage of the study on the grounds of spatial model, the formation of brittle fracture zone with relief slots both along the length of the excavation and advance relief holes had been studied. Based on spatial calculations, the growth of limit-state area along the length of the excavation (figure 3), including relief holes, was observed.

Size assessment of brittle fracture zones along the length of the mine tunnel is made based on elasticity solution, which does not include stress redistribution due to the rocks reaching their limit state. At the same time, it is seen that the growth of brittle fracture occurs in the bottom-hole zone, and mostly at the distance equal to the width of the excavation, the development of this area is completed. Thus, if significant geomechanical and geodynamic processes caused by the excavations are expected, it is necessary to perform the advanced unloading of the rock mass.

According to the results of this study, important practical conclusions were made, namely: - relieve slot significantly reduces outline stress and reduces rock area, potentially dangerous for the loss of stability, and therefore is an effective way for safety operations at the mines of Kirovsk branch of JSC «Apatit»;

- after development of interhole pillars (after dynamic rockfall) in the extraction area or around an additional fracture zone connected with a decrease in rock strength may form over the time (fatigue rock strength), it means that supports systems in these areas must be designed considering this factor. It is also worth noting that the results are fully correlated with the results of full-scale measurements carried out at the mines of Kirovsk branch of JSC "Apatit". The examples of cross sections with brittle fracture are shown in figure 4. 
Table 2. Dimensions of brittle fracture near the excavations under various mining and geological conditions

\begin{tabular}{|c|c|c|c|c|}
\hline \multirow{2}{*}{$\begin{array}{c}\text { Inclination of } \\
\text { principal stresses }\end{array} *$} & \multirow{2}{*}{$\begin{array}{c}\text { Time for brittle fracture } \\
\text { formation }\end{array}$} & \multicolumn{3}{|c|}{ Size of brittle fracture } \\
\cline { 3 - 5 } & $\frac{\sigma_{\theta \max }}{\sigma_{\mathrm{g} i \mathrm{i}}}=0.5$ & $\frac{\sigma_{\theta \mathrm{max}}}{\sigma_{\mathrm{gi}}}=0.7$ & $\frac{\sigma_{\mathrm{g} \max }}{\sigma_{\mathrm{gi}}}=$ \\
\hline \multirow{2}{*}{$15^{0}$} & Straight after excavations & 0.22 & 0.89 & 1.85 \\
\cline { 2 - 5 } & $\begin{array}{c}\text { Upon reaching long-term } \\
\text { strength }\end{array}$ & 0.39 & 1.15 & - \\
\hline \multirow{2}{*}{$30^{0}$} & Straight after excavations & 0.19 & 0.85 & 2.03 \\
\cline { 2 - 5 } & $\begin{array}{c}\text { Upon reaching long-term } \\
\text { strength }\end{array}$ & 0.34 & 1.18 & - \\
\hline & Straight after excavations & 0.26 & 0.81 & 1.72 \\
\cline { 2 - 5 } & $\begin{array}{c}\text { Upon reaching long-term } \\
\text { strength }\end{array}$ & 0.46 & 1.07 & - \\
\hline
\end{tabular}

Note: * The inclination of the areas of principal stress relative to the global coordinate system
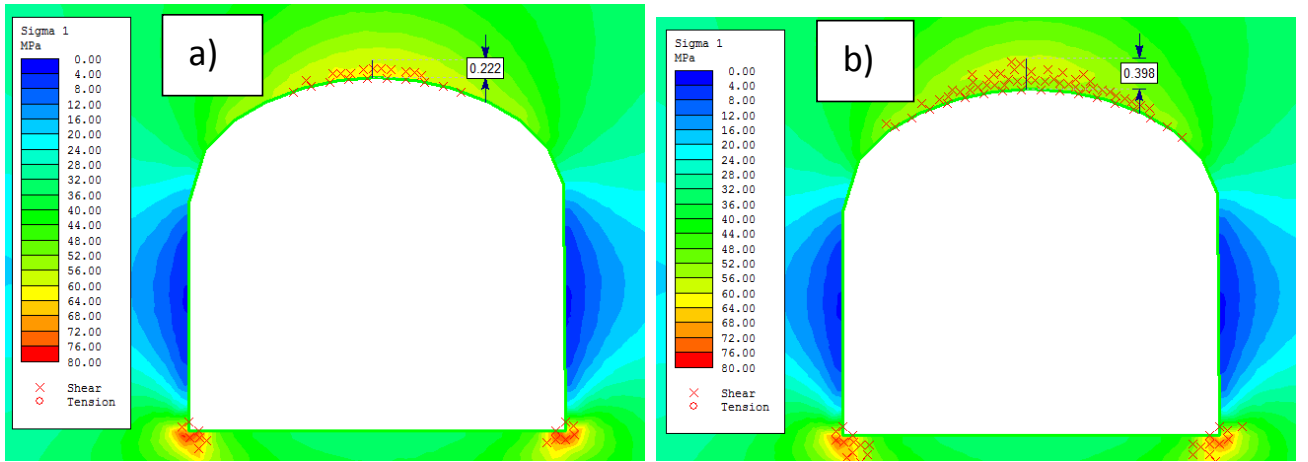

Fig. 1. Distribution of maximum principal stresses and size of brittle fracture zone in the peripheral outline area (ratio of principal stresses 30:15:15): $a$ - in straight and b - long-term strength, the angle of inclination of principal stresses is

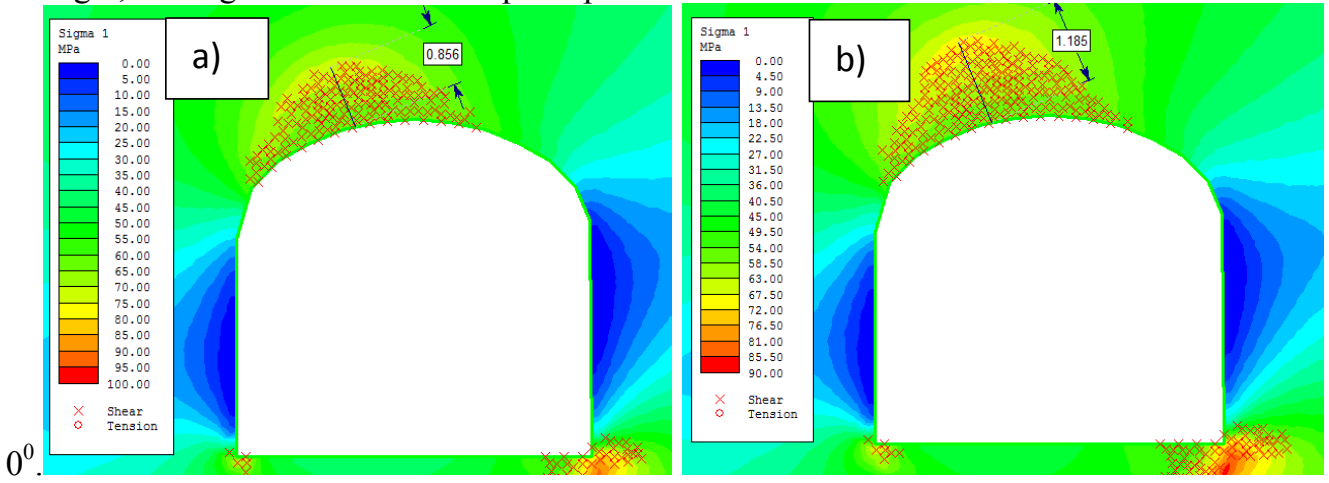

Fig. 2. Distribution of maximum principal stresses and size of brittle fracture zone in the peripheral outline area (ratio of principal stresses 40:20:15): a - in straight and b - long-term strength, the angle of inclination of principal stresses is $15^{\circ}$. 

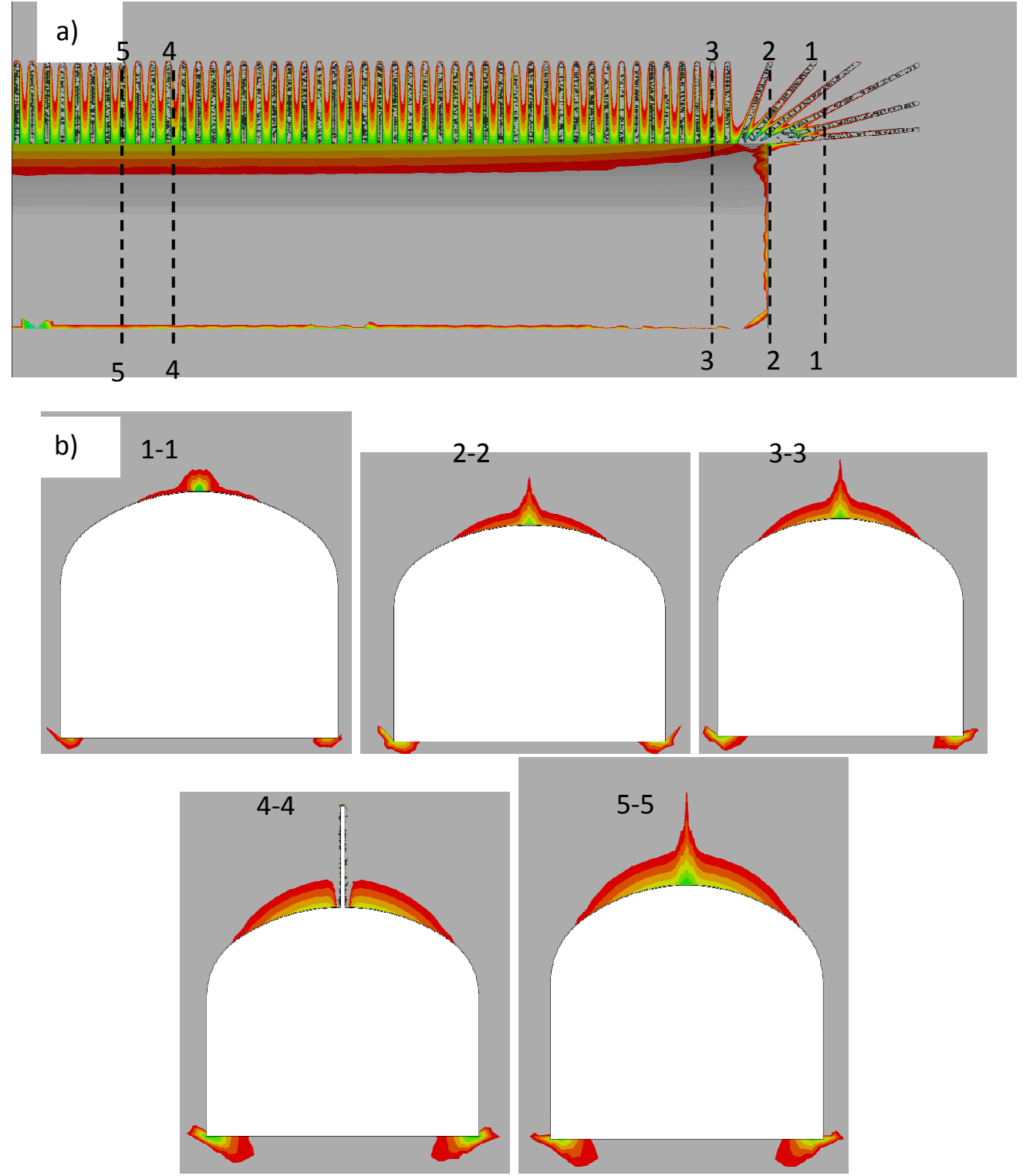

Fig. 3. The size of limit-state area, characterizing brittle rock fracture with vertical position of relieve slots (the results were obtained based on elasticity solutions): a - longitudinal section; $\mathrm{b}$ - cross sections along the length of the excavation. 


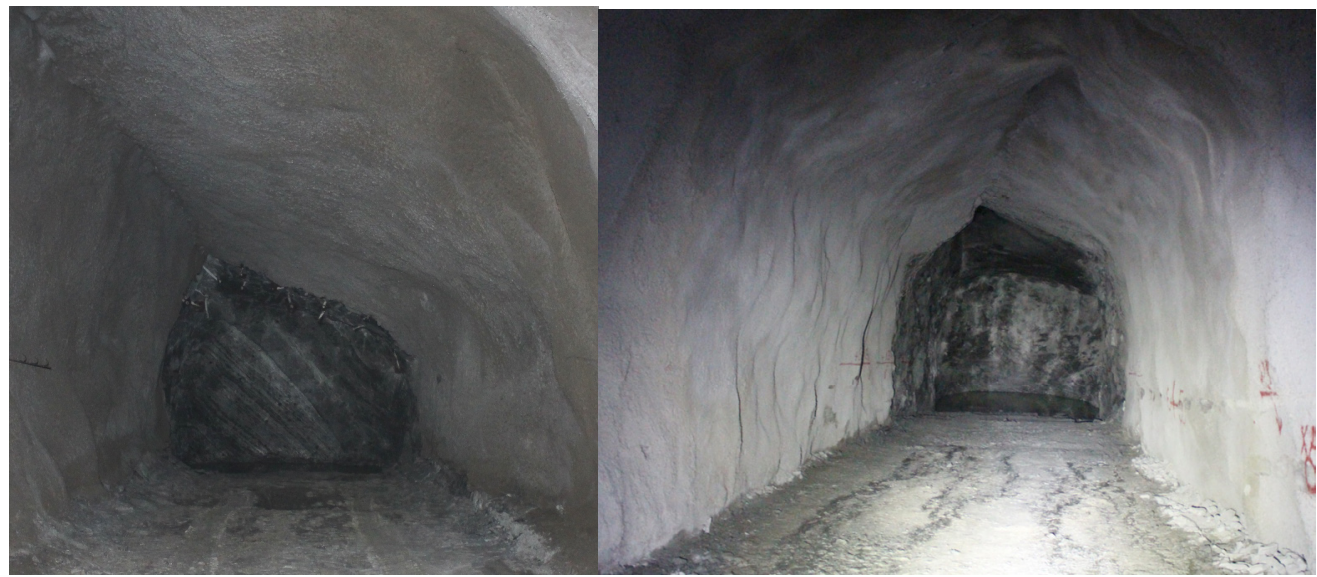

Fig. 4 Brittle outline fracturing at the mines of Kirovsk branch of JSC "Apatit".

\section{Conclusions}

The development of geomechanical processes in highly stressed rock massifs, as shown in the paper, is a very complex process. The forecast of such processes, using the traditional prerequisites for deformation and destruction of rocks, does not allow to obtain reliable sizes of brittle fracture zones. In this paper, a technique has been adapted in which the rock strength mobilization process is not realized immediately, but as micro and macrocracks form and develop, which allows matching between the observed actual zones of brittle fracture of the rock massif in the vicinity of Kirovsk branch of JSC "Apatit" mines and calculated values.

On the whole, the assessment of the geomechanical state of the rock massif in the vicinity of the production located in a highly stressed rock mass allowed not only to determine the size of the brittle fracture zone presented in Table 2, but also to obtain important regularities for practical purposes.

Analysis and processing of the results showed that in the next stage it is necessary to carry out a geomechanical justification for the use of high-performance and reliable ways of fixing and supporting workings in the conditions under consideration, taking into account the results obtained, which will be the subject of further research. It should also be said about the need for joint use of modern measuring complexes that provide reliable registration and indepth analysis of a wide range of geophysical wave fields that vary in space and time $[9,10]$.

\section{References}

1. "Guidelines for safety operations on dangerous and burst-prone deposits (the Khibiny apatite-nepheline deposits)", Apatity-Kirovsk. (2016).

2. C.D. Martin and N.A. Chandler. The progressive fracture of Lac du Bonnet granite. International Journal Rock Mechanics Mining Science \& Geomechanics Abstracts, 31 (6). 643-659. (1994).

3. C.D. Martin, R.S. Read and J.B. Martino. Observations of brittle failure around a circular test tunnel. International Journal Rock Mechanics And Mining Science. 34 (7). 1065-1073. (1997).

4. C.D. Martin, P.K. Kaiser, and D.R. McCreath Hoek-Brown parameters for predicting the depth of brittle failure around tunnels. Can. Geotech. J. 36. 136-151. (1999). 
5. Diederichs M.S., Carter T., Martin D. Practical rock spall prediction in tunnels. Proceedings of the 2010 World Tunnelling Congress, Tunnelling Association of Canada, Richmond, paper 517. (2010).

6. Cai M., Kaiser P. K., Tasaka Y., Maejima T., Morioka H., Minami M. Generalized crack initiation and crack damage stress thresholds of brittle rock masses near underground excavations. International Journal of Rock Mechanics and Mining Sciences. 41(5). 833-847, (2004).

7. Ortlepp W D. Observation of mining-induced faults in an intact rock mass at depth. International Journal of Rock Mechanics and Mining Sciences. 37(1/2), 423-436, (2000).

8. Potvin Y. Surface support in extreme ground conditions-HEA Mesh. In: Safe and Rapid Development in Mining. Perth, Western Australia, 111-119, (2009).

9. I. Yu. Rasskazov, A. V. Gladyr, P. A. Anikin, V. S. Svyatetskiy, B. A. Prosekin, Mining Journal, 8, 9 (2013).

10. A. V. Gladyr, Mining Information and Analytical Bulletin, 6, 220 (2017). 